\title{
Self-Inflicted Supply Risk: An Empirical Investigation
}

\author{
Sam K. Formby \\ Department Computer Information Systems and Supply Chain Management \\ Walker College of Business, Appalachian State University, USA \\ Email: formbysk@appstate.edu (Corresponding Author) \\ Manoj K. Malhotra \\ Jeff Bates Professor and Chair, Department of Management Science \\ Moore School of Business, University of South Carolina, USA \\ Email: Malhotra@moore.sc.edu
}

\begin{abstract}
This study seeks to better understand how internal firm decisions and the design of procurement processes affect supply risks and supply lead times. An in-depth field study was conducted through an interview process with experienced professional buyers from an integrated procurement, logistics, and materials management organization of approximately 300 staff members who manage $\$ 350$ million annually in procurement spending. This organization serves a large manufacturing complex with seven manufacturing centers. Empirical lead-time data on approximately 58,000 procurement transactions completed in a six-month period were collected and analyzed. Results of the field study interviews and mixed effects multi-level analysis of procurement data found that supply decisions made by the plant operations staff before the procurement requests ever reach the buyer organization are a major driver of supply risks and extended lead-times. In addition, the most significant supply risks may not be related to the direct production inputs, but to the procurement of infrequently purchased direct and indirect material supplies needed to maintain factory reliability.
\end{abstract}

Keywords: Sourcing, Supply Risk, Procurement decisions, Strategic sourcing, Just-in-time.

\section{INTRODUCTION}

For over twenty years there is a wide-spread recognition of the fact that risks of supply disruptions have increased significantly in today's global market place that is largely characterized by interlocking and widely dispersed supply chains (Christopher and Lee 2004; Zsidisin et. al. 2005). Significant supply chain disruptions have been occurring with such great frequency (Blackhurst et al. 2005) that $69 \%$ of chief financial officers, treasurers, and risk managers in Global 1000 companies consider supply chain risk a major threat to revenue sources (Elkins et al. 2005). As the rate of supply chain disruptions nearly tripled between the years 1989-2000, shareholders have begun to view them as significant negative events that warrant reductions in firm's share price (Hendricks and Singhal 2003 and 2005). Most recently in a study released by GT Nexus, 2016, researchers found that $40 \%$ of manufacturers reported a supply disruption that impacted business in the past 12 months.

While a number of causal factors have been suggested as contributing to a firm's supply chain disruptions (Chopra and Sodhi 2004, Stecke and Kumar 2009), a fundamental aspect of supply chain risk may simply be the supply risk that occurs on the inbound side of the procurement process (Zsidisin et al. 2005). However, there is little understanding of how functional decisions made inside a firm contribute to supply risk. Consequently, our study focuses on better understanding the genesis and sources of supply risk resulting from decisions internal to the firm, along with quantitatively examining how these decisions affect supplier lead-times and thus contribute to altering a firm's supply risk.

Additionally, the motivation for this research was prompted by practitioner feedback following discussions of supply and supply chain risks in several professional meetings. Many of the practitioners present felt that traditional risks associated with external suppliers were well understood and standard risk management and mitigation practices can be effectively utilized when risks are recognized. These practices included such things as supplier qualification programs, performance monitoring, inspections, required testing and certifications, and supplier redundancy, etc. However, anecdotally, a number of the practitioners present suggested that the more serious risks emanated from within their organizations where decisions were made that sometimes created serious procurement challenges.

\section{BACKGROUND LITERATURE}

Even though an increasing body of operations and logistics management literature is emerging that addresses different aspects of supply chain risks (Lewis 2002; Svensson 2002; Barry 2004; Cavinato 2004; Peck 2005; Juttner 2005; Blackhurst, et al. 2005; Wagner and Bode 2008; Pettit et al. 2013; Macdonald and Corsi 2013), the overall topic remains a relatively unexplored area of research. 

Operations and Supply Chain Management 9(3) pp. 161 - 171 (c) 2016

Stecke and Kumar (2009) provide a comprehensive review of extant literature, but much of it is case-based and in the early stages of theory development. Notably lacking in this extant literature is research related to how internal firm decisions affect risks and lead-times.

Table 1 Extant Literature of Supply Risk Factors

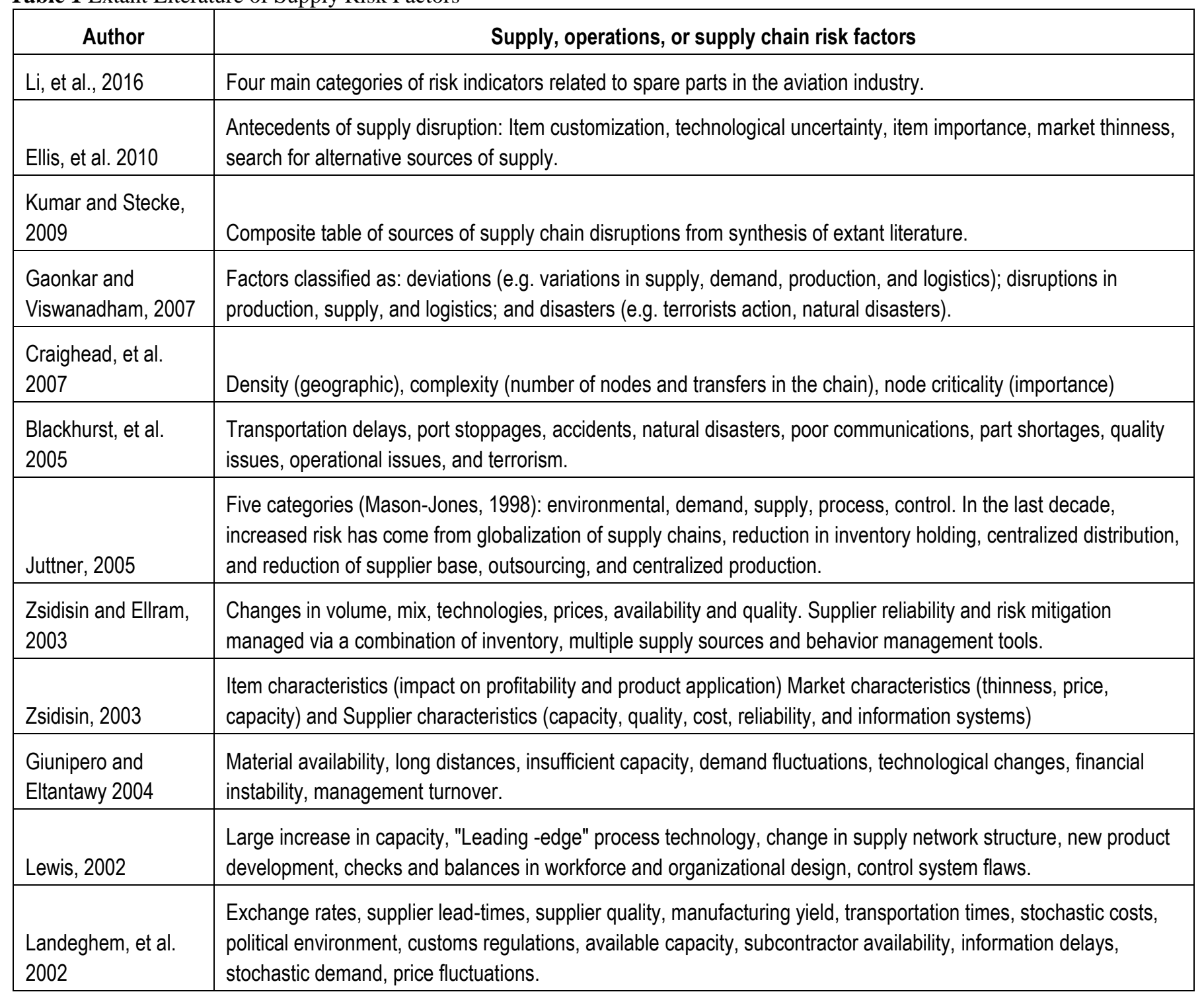

Research addressing supply risk from an external perspective is more common in operations (Zsidisin 2003a), and has been approached from several theoretical perspectives. For example, Zsidisin and Ellram (2003) investigated the role of early supplier involvement in supply risk management utilizing Agency Theory. Li and Choi (2009) utilize Social Network Theory to gain insights into significant managerial problems related to outsourcing. Skilton and Robinson (2003) apply Normal Accident Theory to supply network failures and highlight issues of complexity. Pathak, Dilts, and Mahadevan (2003) examine issues related to the evolution of supply networks by utilizing simulation and elements of Complex Adaptive Systems Theory. Ellis et al. (2010) examine elements of behavioral risk and exchange theories to investigate how product and market risk factors affect buyer perceptions of supply risk and decisions to seek alternative sources. Wagner and Bode (2013) discuss a contingency perspective on supply chain risk and acknowledge that the internal and external context of the organization affect risks. The application of each of the aforementioned theoretical lenses in these studies has provided new insights into risks and business challenges between firms and their suppliers, but yielded very limited insights into the contributions of inter-firm decisions to those risks.

Table 1 lists some of the more recent studies on the supply risk factors found in literature. Among the two studies that best articulate perceived risk factors, Zsidisin (2003b) examined managerial perceptions of supply risk using a case 
study approach, and created a classification scheme of perceived supply risk characteristics based on item, market and supplier attributes. Building upon this study, Ellis et al. (2010) concluded, "The process through which buyers make decisions in the face of these risks has not been explored." Consequently they empirically examined buyer's perceptions of risks of supply disruption related to item and supplier availability, and identified four antecedents of supply disruption risk: technology uncertainty, market thinness, item customization, and item importance. However, neither study investigated the origins of these risks in the decisions made before the procurement requests reach buyers. Table 1 further confirms that none of the studies explore how the decisions made internal to the firm during the procurement process contribute to supply risk.

\section{RESEARCH METHODOLOGY}

\subsection{Background Information and Context}

This study was conducted at a large industrial complex operated by a joint partnership corporation between four international companies and several minor partner companies. The identity of this complex is not mentioned here for protecting the confidentiality as requested. Approximately 11,000 employees are employed at the complex, which operates a diverse set of industrial facilities ranging from common low hazard industrial operations to complex high hazard operations. The complexity of operations is reflected in the diversity of procurement actions involving commodities, services, and engineered products. Procurement for these different types of products spans a wide range of business processes and control issues, from simple commercial procurements to procurements involving very specialized engineering and manufacturing techniques. Stringent quality assurance and quality control requirements are enforced.

The procurement organization within this industrial complex consists of about 300 people, who manage the procurement process dealing on an average with approximately 135,000 actions per year valued at $\$ 350$ million in annual spending. They also manage receipt, storage, and distribution of most items until needed for use. Their internal customers include staff in production and operations, maintenance, engineering, project management, administrative services, and R\&D organizations. The procurement professionals who provided the qualitative portion of our data through detailed interviews averaged 20+ years of experience, and many are active in the National Contract Management Association (NCMA), the Institute for Supply Management (ISM), and the National Property Management Association (NPMA). Over forty individuals in the organization are NCMA Certified Professional Contract Managers (CPCM), ISM Certified Professionals in Supply Management ${ }^{\circledR}($ CPSM $®)$ or NPMA certified property managers. Five are NCMA fellows. Although the experience and qualifications of the procurement staff are excellent, the procurement experience levels of their in-plant customers vary significantly, thereby requiring well defined processes and procedures with checks and balances based on the risks of the action being planned. Overall, very high quality is demanded in this setting, and there is low tolerance for failures in any aspect of operations.

This industrial complex was chosen because of the diversity and volume of procurement actions, the experience and knowledge of procurement staff with respect to the best practices and processes, connections to corporate and professional societies, and a culture demonstrating a long history of root cause evaluation of problems and continuous improvement.

\subsection{The Internal Procurement Process}

The internal processes of the complex are centered on five procurement process stages similar to those described by Johnston and Lewin (1996). The five stages, shown in Figure 1, include procurement planning, specification, solicitation, source selection, and contract administration/closeout steps. The field study interview process was designed using these five procurement process stages as the outline for our investigation. Following several preliminary questions, each buyer interviewed was asked questions about the types of problems that occur in each of the five procurement process steps, with an emphasis being placed on the source of those problems in processes and decisions made internal to the firm before procurement requests reached them.

Based on the interviews and an examination of the information provided by the firm, four different procurement mechanisms characterizing the purchasing processes were characterized. These mechanisms are referred to as just-in-time (JIT) contracts, basic order purchases, credit card purchases, and standard purchase requisitions. They are listed here in order of their frequency of use, and each mechanism is explained below. While strategic sourcing has been discussed in many publications (Anderson and Katz 1998; Tanriverdi et al. 2007), we did not find any other study in our literature search that isolates and discuses all four of these mechanisms in a comparative fashion. So the level of detail and description of how these mechanisms are used as part of a composite procurement strategy is one of the unique contributions of our study.

For the most commonly purchased items, just-in-time contracts are used, while for the least common items, standard purchase requisitions are used. It should be clarified that at this industrial complex, the term just-in-time refers to contracts were the suppliers were required to maintain inventory either on the plant site or in very close proximity and the procurement process was preapproved so that operations staff down to the first line supervisors could make the purchases for his/her desktop computer, without other approvals or purchasing support. The term used at this industrial complex does not refer to the continuous or pull flow concepts utilized in the Toyota production System. The just-in-time contracts provide a very efficient, responsive, and predictable mechanism for acquiring most of the materials needed to support routine operations. In contrast, the standard purchase requisition process is required when there is no prior arrangement with a supplier for the material desired. Also described in the interviews were three levels of quality assurance controls imposed on the procurement process based on item importance and complexity, 
and the perceived risk of failure. Quality assurance (QA) level 1 , the most stringent level, typically requires verification of supplier qualifications and processes and functional testing of products before introduction into the operation. QA level 2 procurement actions typically require formal functional acceptance tests and inspections upon receipt. Finally, QA level 3 , the least stringent level may only require formal receipt inspections and minimal verification of specifications being met. While these levels are uniquely defined for this organization's processes, their requirements are quite generalizable since they are based on those found in the joint engineering standard, ANSI/ASME NQA-1-2008, by the American National Standards Institute (ANSI) and American Society of Mechanical Engineers (ASME).
Following the interviews, quantitative data related to supply lead-times was also examined for the most recent six months representing approximately 58,000 procurement actions. Supply lead-time is defined as the elapsed interval from when the order is placed with a supplier to when the order is closed (received and accepted) in the procurement system. It includes supplier lead-time and the time required to perform all quality assurance activities and internal logistics to get the material to the internal customer. A statistical analysis of this data was performed to evaluate the responsiveness of the procurement mechanisms, as well as systematically isolate the effects of quality assurance and other process decisions on supply lead-times.

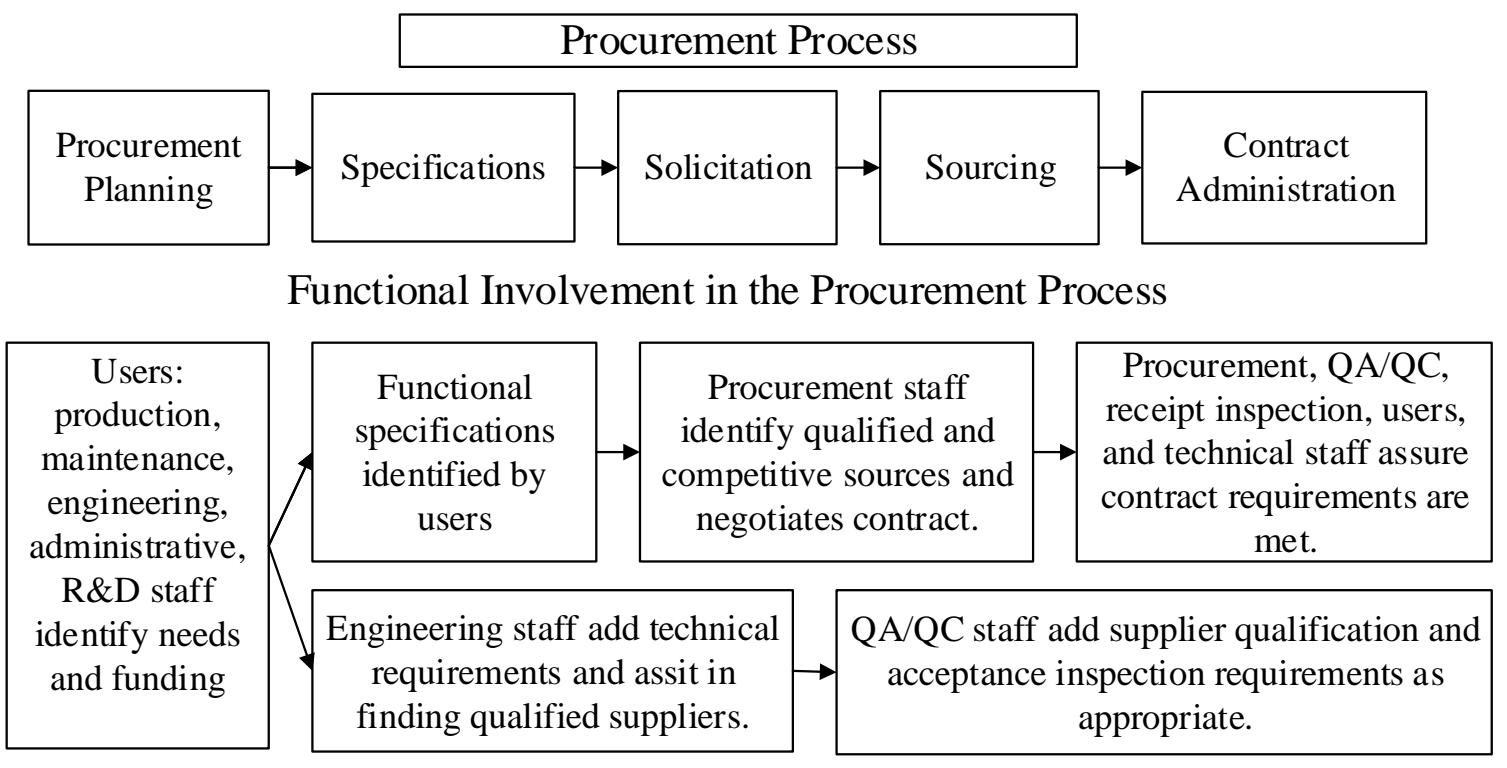

Figure 1 Procurement Life Cycles and Processes

\subsection{Empirical Analysis of Supply Lead-time Data}

Juttner et al., 2003, defined supply chain risk as "any risks for the information, material and product flows from original supplier to the delivery of the final product for the end user." Zsidisin, 2003a, defined supply risk as "the probability of an incident associated with inbound supply from individual supplier failures or the supply market occurring, in which its outcomes result in the inability of the purchasing firm to meet customer demand or cause threats to customer life and safety." Because we are looking within the firm at the initial identification of need, we extend these definitions and identify the end user, internal customer within the firm, as the person who identified the need and we the risk of the procured item not reaching that customer before a negative operational impact occurs. For example, if a maintenance worker has requested parts, and they don't arrive at the point of need within the factory before being a production impact occurs, then the risk has resulted in a negative consequence. Lack of availability of maintenance spare parts is a major concern for long field life systems. Though beyond the scope of this study, Li et al. 2016 describe four main categories of risk indicators related to spare parts in the aviation industry and many of these indicators relate well to long life manufacturing systems as well.

If supply lead-time exceeds the time from identification of the need to the scheduled use of the item in operations, then adverse operational impacts are likely. The decisions made by a firm in designing the procurement processes also affect supply risks. Zsidisin (2003b) noted that firms design procurement processes utilizing inventory buffers, redundant sources, and various forms of supplier collaboration in order to manage perceived supply risks. These design decisions are aimed at best serving operational needs while reducing uncertainty and risks.

The procurement process at our study organization utilized primarily four procurement mechanisms or strategies. Two of these mechanisms, Just-in-time (JIT) and Basic Order purchases, flow through approximately eighty strategic sourcing agreements established with regional suppliers. Each strategic sourcing agreement is a categorical distinction, and is set up to cover commodity types such as fire protection equipment, stainless steel piping and valves, bulk chemicals, etc. These strategic agreements exhibit many of the characteristics and benefits commonly associated with early 
supplier involvement, (Zsidisin and Smith 2005). For procurement actions most frequently needed to sustain routine operations, just-in-time (JIT) contract requirements are maintained within the strategic sourcing agreements. The JIT contract terms are specific to several thousand routinely needed items, allow for orders to be placed electronically, and require delivery within a few days or less. Approximately $62 \%$ of all procurement actions were JIT purchases; $3.5 \%$ were QA level 2 and $96.5 \%$ were QA level 3. QA level 1 purchases are not allowed to use the JIT mechanism since much more stringent QA controls are needed and invoked.

For less routine, but common emergent needs, Basic Order contract terms are established in the strategic sourcing agreements. They allow for expedited electronic orders of products available through affiliated manufacturers' catalogs. The Basic Order procurement mechanism accounts for approximately $19 \%$ of the total procurement actions, and is limited to QA level 3. Approximately $81 \%$ of all procurement actions, including JIT and Basic Order purchases, go through these strategic sourcing agreements. As a back-up or contingency process, a corporate Credit Card system allows users (with administrative controls) to go directly to other suppliers for items generally not available in the time required through the strategic sourcing agreements. Approximately $12 \%$ of the total procurement actions are Credit Card purchases, and all are limited to QA level 3.

The most time consuming and onerous procurement mechanism is the individual Procurement Requisition Process, which is often needed for complex, unique, or non-routine, emergent procurement actions with high importance. These procurement actions typically involve one or more of the following attributes which generally increase supply lead-time and procurement process complexity--additional quality assurance controls, proprietary technology, product customization, product obsolescence, and limited availability. The majority of requisitions at this location are for emergent needs processed in support of routine operations. Approximately $7 \%$ of all procurement actions utilize the purchase requisition process mechanism.

When an internal customer identifies a new procurement need, it is first assigned a QA level based on operational importance. Based on the QA level, only certain process mechanisms may be used to fill the need. It is highly desirable to utilize the strategic agreements whenever possible to minimize the supply lead-time, transaction costs, and procurement uncertainty. Figure 2 shows a process flow diagram illustrating the possible flow routes of a procurement action.

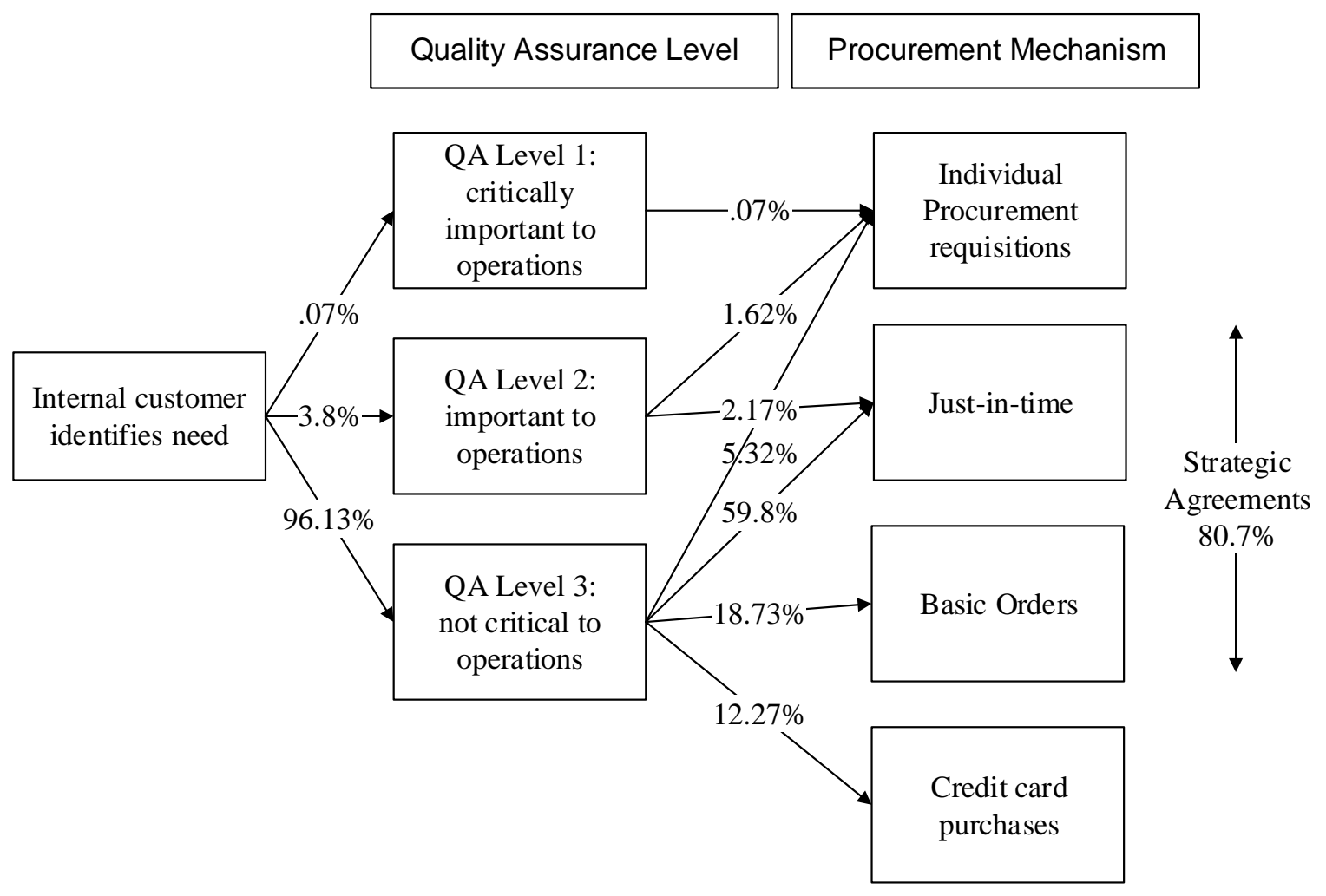

Figure 2 Procurement Process Flow Diagram

From an identification of a need by an internal user through fulfillment of that need, there are seven process pathways that a procurement action can flow. Table 2 shows the seven pathways, along with the corresponding comparative statistics that reiterate the significance of the lead-time differences resulting from internal decisions and procurement process choices made. It is interesting to note that the coefficient of variation increases as the procurement process 
flow pathway gets shorter and is above 1.0 for the three fastest pathways. The differences here are largely explained by the differences in inventory levels maintained by commodity type and relative predictability of need and urgency of replenishment. Not all commodity types have the same contractually required delivery times. For example, piping and instruments may have a two day required delivery times, and chemicals may have an eight day delivery requirement.

Table 2 Procurement Process Flow Pathways and Descriptive Statistics

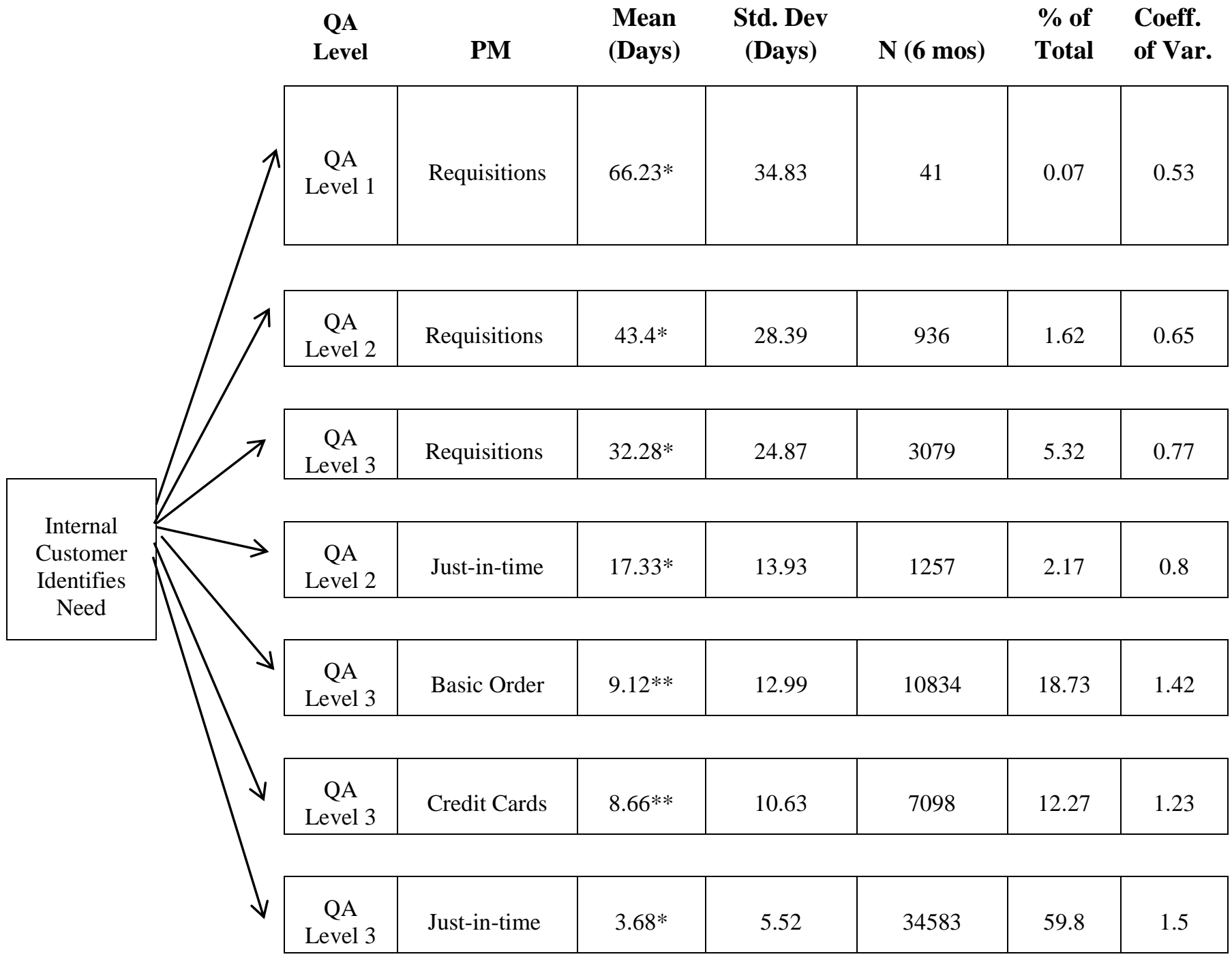

Note: Based on Tamhane T2 Multiple comparison test, different from other means: * $\mathrm{p}<.05, * * \mathrm{p}<.06$

The unpredictability of a need can result in short leadtimes before operations are disrupted. The poor availability can also extend supply lead-times to delivery. From the previous six months of data made available at the time of the interviews, we examined the supply lead-times segmented by each procurement mechanism and at each quality assurance level. We also examined the variance among the strategic sourcing agreements. The empirical analysis of the supply lead-times is done in three parts. First, descriptive statistics show the volumes of procurement actions, and means and standard deviations of lead-times within each procurement mechanism and QA level. We then performed an ANOVA and Tamhane
T2 multiple comparison tests to verify that there are significant differences between the mean lead-times of the different procurement mechanisms. Lastly we conducted multi-level or mixed effects modeling to find out how much variance is explained by QA level, procurement mechanism type, and strategic sourcing agreement.

At an average of 4.16 days, the JIT mechanism is clearly the most responsive procurement mechanism. The Basic Order mechanism averages just a little less than 10 days. However, the items requiring the Purchase Requisition mechanism take an average of 33-66 days, depending on the QA level. Because unique, important, emergent needs often require the lengthiest 
procurement mechanism; their potential for disruption is the greatest. The inability to forecast unique and important needs critical to continuity of operations, coupled with the longer supply lead-times, becomes a serious driver of supply disruption risk. From the interviews with the buyers, this forecasting weakness is most often attributed to the inexperience of the internal customers responsible for identification of procurement needs. The quantitative analysis thus empirically confirms the buyers' assertions during the interviews about the most serious supply disruption risks.

To test for differences in lead-times for the different procurement mechanisms and quality assurance levels, an ANOVA was performed on the supply lead-time data. Table 2 reports the volumes, means and standard deviations of the study variables, while Table 3 reports the ANOVA results, which basically confirm that many of the differences reported in Table $\mathbf{2}$ are statistically different from one other. However, ANOVA cannot tell us exactly which ones and whether all the subgroup differences under a given subgroup variable are different from all other subgroups. Only a multiple comparison test can do so. Since Levene's test on our data confirmed that the equal variance assumption is violated, the Tamhane T2 multiple comparison test is the most appropriate post-hoc test of predicted means differences (Tamhane 1977). The Tamhane $\mathrm{T} 2$ tests confirm that all procurement mechanism means in Table 2 are different at $\mathrm{p}<.05$, except for the mean lead-time of credit card purchases and basic order agreement purchases, which are different at $\mathrm{p}<.06$. Therefore the mean supply leadtime for each procurement mechanism is statistically different from each of the other three procurement mechanisms.

Table 3 ANOVA Results for Supply Lead Time as the Dependent Variable

\begin{tabular}{|l|r|r|r|l|}
\hline \multicolumn{1}{|c|}{ Source } & \multicolumn{1}{c|}{$\begin{array}{c}\text { Type III Sum } \\
\text { of Squares }\end{array}$} & \multicolumn{1}{c|}{ df } & \multicolumn{1}{c|}{$\begin{array}{c}\text { Mean } \\
\text { Square }\end{array}$} & F value \\
\hline Corrected Model & $3.89 \mathrm{E}+06$ & 5 & 778490.8 & 6783.466 \\
\hline Intercept & 302042.143 & 1 & 302042.1 & 2631.878 \\
\hline Procurement Mechanism & 351718.006 & 2 & 175859 & 1532.367 \\
\hline QA Level & 2777665.548 & 3 & 925888.5 & 8067.833 \\
\hline Error & 6635824.818 & 57822 & 114.76 & \\
\hline Total & $1.41 \mathrm{E}+07$ & 57828 & & \\
\hline Corrected Total & $1.05 \mathrm{E}+07$ & 57827 & & \\
\hline \multicolumn{2}{|r|}{ R Squared $=.370$ (Adjusted R Squared $=.370$ ), $p<.001$ for all variables. } \\
\hline
\end{tabular}

In addition, several mixed effects multilevel models were evaluated to determine how much variance in mean supply lead-times is explained by differences in QA level, procurement mechanism, and strategic sourcing agreement. Table 4 provides the results from intercept only, mixed-effects models using maximum likelihood estimation (Rabe-Hesketh and Skrondal 2008). With this methodology, we examined the variance in the means of the subgroups by grouping variables specified in each model. The intercepts are the means of subgroups within each model. We did not include other terms because there was insufficient data in all the subgroups within groups to make these types of tests, and even if they were possible and valid, interpretation would have been difficult and highly speculative. The equations for each model are shown below to clarify the analytical results. The base model is first specified by equation 1 .

$$
Y \mathrm{ij}=\beta 0 \mathrm{j}+\mathrm{rij}
$$

where supply lead-time $Y$ for an individual procurement action $\mathrm{i}$ nested in QA Level $\mathrm{j}$ is equal to the mean lead-time, $\beta 0 \mathrm{j}$, of all procurement actions in QA Level $\mathrm{j}$ plus an individual-level error rij. Because QA Level has an effect common to all procurement actions within a given level, it is necessary to add a QA Level error term. This is done by specifying a separate equation for the intercept

$$
\beta 0 \mathrm{j}=\gamma 00+\mu 0 \mathrm{j}
$$

where $\gamma 00$ is the average lead-time for the total population of procurement actions and $\mathrm{u} 0 \mathrm{j}$ is the mean QA Level $\mathrm{j}$ effect. Combining equations 1 and 2 yields,

$$
\text { Yij }=\gamma 00+\mu 0 \mathrm{j}+\mathrm{rij}
$$

Denoting the variance of rij as $\sigma 2$ and the variance of $\mu 0 \mathrm{j}$ as $\tau$ oo, the percentage of observed variation in lead-time attributable to QA Level is found by dividing $\tau$ oo by the total variance $\sigma 2+\tau$ oo. Using maximum likelihood estimation, we find that QA Level accounts for $78.6 \%$ of the variation of the individual procurement action lead-times.

With this methodology, we are only investigating variance in the means of the subgroups by grouping variable. The intercepts are the means of subgroups within each model. For example, if you average the means of the QA levels 1, 2, and 3, you get the "Intercept Only" value in Table 4 under the QA level model. The 78\% variance explained in the QA level model says that QA level accounts for most of the variance in those three subgroup means. QA level is thus a significant predictor of supplier lead-time.

This same methodology was used with grouping Procurement Mechanism and Strategic Agreement, which resulted in $55.30 \%$ and $75.73 \%$ variance explained by these variables respectively in Table 4. From these single variable 
models, we conclude that each variable is a significant predictor of supply lead-time. In reality, however, these variables are also nested, and so we must examine the effects of process choices at multiple levels simultaneously. Two additional multi-group models: Strategic Agreement within Procurement Mechanism, and Strategic Agreement within Procurement Mechanism within QA Level are analyzed to evaluate the relative predictive power of these variables. We advance this model to include additional levels with the following equations. First we consider Strategic Agreement within Procurement Mechanism.

$$
\text { Yijk }=\beta o j k+\text { rijk }
$$

The supply lead-time Yijk for an individual procurement action $\mathrm{i}$ nested in a strategic agreement $\mathrm{j}$ within a procurement mechanism $\mathrm{k}$ is equal to the mean lead-time, $\beta 0 \mathrm{jk}$, of all procurement actions in strategic agreement $\mathrm{j}$ within procurement mechanism $\mathrm{k}$ plus an individual-level error rijk.

$$
\beta 0 \mathrm{jk}=\gamma 00 \mathrm{k}+\mu 0 \mathrm{jk}
$$

However, since strategic agreements are nested within procurement mechanism, the mean lead-time, $\beta 0 \mathrm{jk}$, of all procurement actions in strategic agreement $\mathrm{j}$ within procurement mechanism $\mathrm{k}$ is equal to the mean lead-time of all procurement actions in procurement mechanism $\mathrm{k}, \gamma 00 \mathrm{k}$, plus a strategic agreement effect within the mechanism, $\mu 0 \mathrm{jk}$. Furthermore, $\gamma 00 \mathrm{k}$ can be broken down into the mean of all procurement actions and the procurement effect,

$\gamma 00 \mathrm{k}=\zeta 000+\mu 00 \mathrm{k}$

So the total combination of effects is Yijk $=\zeta 000+\mu 00 \mathrm{k}+\mu 0 \mathrm{jk}+$ rijk where the supply lead-time of procurement action Yijk is equal to the sum of the mean lead-time of all procurement actions, plus the procurement mechanism effect, plus the strategic agreement effect within the procurement mechanism, plus the individual error. Using mixed-effects multi-level modeling methodology with maximum likelihood estimation (RabeHesketh and Skrondal 2008), we summarize the results in Table 4. The last model in Table 4, Strategic Agreement within Procurement Mechanism within QA Level, is calculated with a similar methodology.

Percent variance explained in group means, from with-in group correlations, is reported in Table $\mathbf{4}$ and shows that individually all three categorical variables are significant predictors of supply lead-time. When we examine strategic agreement purchases nested within procurement mechanism for only the QA level 3 procurement actions, we see that the strategic agreement is a more significant predictor of supply lead-time. Lastly, when we examine strategic agreements (SA) nested within procurement mechanisms, nested within QA levels, we find that SA is the most significant predictor of supply lead-time, followed by QA level and procurement mechanism. These results tend to further confirm the conclusions from the earlier qualitative analysis that strategic agreements tend to mitigate the risks of internal customers' lack of experience and knowledge. They also mitigate the risks of short-notice emergent needs by lowering procurement processing and supply lead-times and providing greater predictability in meeting operational needs.

\begin{tabular}{|c|c|c|c|c|c|}
\hline Model & $\begin{array}{c}\text { QA Level, All } \\
\text { data, } \\
\mathrm{N}=57,853\end{array}$ & $\begin{array}{c}\text { Procurement } \\
\text { Mechanism, All } \\
\text { data } \quad \mathrm{N}=57,853\end{array}$ & $\begin{array}{l}\text { Strategic Agreement, } \\
\text { (SA) data only } \\
N=42,767\end{array}$ & $\begin{array}{l}\text { Only QA Level 3: Grouped } \\
\text { by PM then SA within PM } \\
\qquad N=41,278\end{array}$ & $\begin{array}{c}\text { Grouped by QA } \\
\text { Level then PM } \\
\text { within QA Level, } \\
\text { then SA within } \\
\text { PM. }\end{array}$ \\
\hline Parameters & \multicolumn{5}{|c|}{ Fixed Effects Intercept Only: Coefficient (Std. Error) } \\
\hline \multirow[t]{2}{*}{ Intercept Only } & $33.80(14.12)$ & $14.29(6.12)$ & 15.42(1.79) & 16.02(3.94) & $27.94(8.78)$ \\
\hline & \multicolumn{5}{|c|}{ Random Effects (percentage of total variance explained) } \\
\hline QA Level & $78.60 \%$ & & & & $28.34 \%$ \\
\hline $\begin{array}{c}\text { Procurement } \\
\text { Mechanism (PM) }\end{array}$ & NA & $55.30 \%$ & NA & $20.06 \%$ & $20.87 \%$ \\
\hline $\begin{array}{c}\text { Strategic } \\
\text { Agreement (SA) }\end{array}$ & NA & NA & $75.73 \%$ & $52.65 \%$ & $37.62 \%$ \\
\hline Residual Error & $21.40 \%$ & $44.70 \%$ & $24.27 \%$ & $27.29 \%$ & $13.17 \%$ \\
\hline
\end{tabular}

Table 4 Multilevel Mixed Model Results 


\subsection{Interpretation of Procurement Mechanism Analysis}

At this point, let's clarify again the definition of supply lead time as it relates to the perspective of the internal customer within the company. We recognize that the concept of supply lead time in operations literature generally refers to the time between when a company places an order and when the supplier delivers it to the company. However, in this study, we identified the internal operations customer who identifies the procurement need as the principle customer. So total supply lead time from his/her perspective is the time from identification of the need to the procurement organization until operations receives the product for use. This total supply lead time measurement includes the supplier lead time (time it takes for the supplier to deliver the product) plus the internal purchase lead time (time from identification of the need to placement of the order with a supplier). The total supply lead time between when a need is identified to the procurement organization and when the order is received by the operations staff, increases by almost a factor of 10 between the JIT mechanism used for frequently purchased items and the procurement requisition mechanism used for generally infrequently purchased items. Total supply lead time also increases by almost a factor of 10 as the quality assurance level increases from QA level 3 for general use items to QA level 1 for the most important and complex items. In addition, it appears that the increased lead time effect of the QA level increases as the procurement mechanism transitions from the more frequently used JIT mechanism to the less frequently used purchase requisition mechanism. However, from looking at the coefficient of variations (CV) shown in the last column of Table 2, we also conclude that the higher levels of QA may actually increase predictability because all CV's of QA level 2 and 1 purchases are less than 1, and all CV's of QA level 3 purchases are greater than 1 .

The origins of supply risks start with anticipation of needs and proper planning to assure that the procurement processes can respond in sufficient time to prevent operational impact. Internal firm decisions made before the requests get to the procurement organization can significantly increase procurement lead-time and in many cases increase supplier lead time. So the risk of operational impact is increased by the need not being met for a longer period.

\section{CONCLUSIONS AND FUTURE RESEARCH DIRECTIONS}

Although a number of findings of this study are likely generalizable based on the breadth and diversity of the experience of the buyers interviewed, scope of operations involved, and standard use of processes and best practices promoted by the procurement professional societies, the indepth study of a single organization cautions us not to declare broad applicability. Every organization has uniquenesses which make generalizability a challenge. Though the problems identified in this firm are likely to be common in many organizations, the severity and relative ranking of the issues may vary considerably based on the experience of the procurement staff, the internal customers, and rigor of the procurement processes existing at a particular firm.

On the other hand, we also recognize that the organization we investigated is large, diverse, and fairly representative of procurement challenges and complexities that would normally be found in many other firms of similar size and scope. This manufacturing complex also has a technically strong and very experienced staff of procurement professionals who have worked in many locations around the world, and the companies involved employ rigorous processes with embedded quality assurance requirements based on the importance of each procurement action.

From the perspective of the experienced procurement specialists, we learned that the root causes of supply risks hardest to control are found in internal firm decisions often made before procurement requests reach the organization's buyers. The most significant internal challenge to the firm is the ability to plan its needs with sufficient lead-times, especially for important and/or complex items that are rarely ordered. In future research, the procurement processes need to be further investigated to find mechanisms for earlier identification of needs and processes to reduce supply leadtimes for emergent needs. Future research should also evaluate the value of real-time collaborative purchasing decision support systems (DSS) as discussed by Miah et al. 2013. The limitations of linear or compartmental decision processes as described in this research can likely be significantly improved through real-time collaborative DSS, with improvements similar to those found in concurrent engineering research. Another area of future research should include the growing contribution to supply risk from logistics and courier risks as modeled by Wang et al. 2014 .

In terms of managerial relevance, our research suggests that firms should consider development of strategies that minimize procurement uniqueness and complexity, while maximizing the use of commonly available products. Since no one can foresee all possible emergent needs, anticipation of potentially problematic needs becomes very important in operations. So managers should also consider use of tools and techniques such as fault tree analyses, preventive maintenance programs, and simple reliability theory to identify the most likely failure points that can result in adverse operational impacts. If problem anticipation is done well, then procurement processes can be designed to respond as needed and thereby minimize the costly disruptions. To evaluate the relationship between the SCM implementation method and its performance, we tested our hypothesis using the data answered by 23 manufacturing and logistics companies in Japan. For the analysis, we used two methods: structural equation modelling, and factor analysis. In this section, we report how we collected the data and motivated the use of these methods. 


\section{REFERENCES}

Anderson, M.G., \& Katz, P.B. (1998). Strategic Sourcing. International Journal of Logistics Management, 9(1), pp. 1-13.

Barry, J. (2004). Supply chain risk in an uncertain global supply chain environment. International Journal of Physical Distribution \& Logistics Management, 34(9), pp. 695-97.

Blackhurst, J., Craighead, C.W., Elkins, D., \& Handfield, R.B. (2005). An empirically derived agenda of critical research issues for managing supply-chain disruptions. International Journal of Production Research, 43(19), pp. 4067-4081.

Cavinato, J.L. (2004). Supply chain logistics risks from the back room to the board room. International Journal of Physical Distribution \& Logistics Management, 34(5), pp. 383-387.

Choi, T.Y., \& Dooley, K.J. (2009). Supply Networks: Theories and Models. Journal of Supply Chain Management, 45(3), pp. 2526.

Chopra, S., \& Sodhi, M.S. (2004). Managing Risk to Avoid SupplyChain Breakdown. MIT Sloan Management Review, 46(1), pp. 53-62.

Christopher, M., \& Lee, H. (2004). Mitigating supply chain risk through improved confidence. International Journal of Physical Distribution and Logistics Management, 34(5), pp. 388-396.

Elkins, D., Handfield, R.B., Blackhurst, J., \& Craighead, C.W. (2005). 18 Ways to Guard Against Disruption. Supply Chain Management Review, 9(1), pp. 46-53.

Ellis, S.C., Henry, R.M., \& Shockley, J. (2010). Buyer perceptions of supply disruption risk: A behavioral view and empirical assessment. Journal of Operations Management, 28, pp. 34-46.

Giunipero, L.C., \& Eltantawy, R.A. (2004). Securing the upstream supply chain: a risk management approach. International Journal of Physical Distribution \& Logistics Management, 34(9), pp. 698-713.

Gaonkar, R.S., \& Viswanatham, N. (2007). Analytical Framework for the Management of Risk in Supply Chains. IEEE Transactions on Automation Science and Engineering, 4(2), pp. 265-73.

GT Nexus, (2016). State of the Global Supply Chain: A Research Report on the Top Issues Facing Industry Executives for 2016 and Beyond. www.gtnexus.com

Hendricks, K.B., \& Singhal, V.R. (2003). The effect of supply chain glitches on shareholder wealth. Journal of Operations Management, 21(5), pp. 501-523.

Hendricks, K.B., \& Singhal, V.R. (2005). An Empirical Analysis of the Effect of Supply Chain Disruptions on Long-Run Stock Price Performance and Equity Risk of the Firm. Production \& Operations Management, 14(1), pp. 35-52.

Johnston, W.J., \& Lewin, J.E. (1996). Organizational Buying Behavior: Toward an Integrative Framework. Journal of Business Research, 35, pp. 1-15.

Juttner, U. (2005). Supply chain risk management, Understanding the business requirements from a practitioner perspective. International Journal of logistics Management, 16(1), pp. 120141.

Lewis, M.A. (2002). Cause, consequence and control: towards a theoretical and practical model of operational risk. Journal of Operations Management, 21(2), pp. 205-224.
Lewin, J.E., \& Donthu, N. (2005). The influence of purchase situation on buying center structure and involvement: a select metaanalysis of organizational buying behavior research. Journal of Business Research, 58, pp. 1381-1390.

Li, M., \& Choi, T.Y. (2009). Triads in Services Outsourcing: Bridge, Bridge Decay, and Bridge Transfer. Journal of Supply Chain Management, 45(3), pp. 27-39.

Macdonald, J. R. \& Corsi, T. M. (2013). Supply Chain Disruption Management: Severe Events, Recovery, and Performance. Journal of Business Logistics, 34(4), pp. 270-288.

Miah, S.J., Ahsan, K. \& Msimangira, K.A., (2013). An approach of purchasing decision support in healthcare supply chain management. Operations and Supply Chain Management: An International Journal, 6(2), pp. 43-53.

Peck, H. (2005). Drivers of supply chain vulnerability: an integrated framework. International Journal of Physical Distribution \& Logistics Management, 35(4), pp. 210-232.

Pettit, T. J., Croxton, K. L. \& Fiksel, J. (2013). Ensuring Supply Chain Resilience: Development and Implementation of an Assessment Tool. Journal of Business Logistics, 34(1), pp. 46-76.

Project Management Institute (PMI) (2008), A Guide to the Project Management Body of Knowledge (PMBOK), Fourth Edition.

Rabe-Hesketh, S., \& Skrondal, A. (2008), Multilevel and Longitudinal Modeling Using Stata, Stata Press Second Edition.

Stecke, K.E., \& Kumar, S. (2009). Sources of Supply Chain Disruption, Factors that Breed Vulnerability, and Mitigating Strategies. Journal of Marketing Channels, 16(3), pp. 193-226.

Tamhane, A.C. (1977). Multiple comparisons in model I one-way ANOVA with unequal variances. Commun. Statist., Ser. B., 9, pp. 167-178.

Tanriverdi H., Konana, P., \& Ge, L. (2007). The Choice of Sourcing Mechanisms for Business Processes. Information Systems Research, 18(3), pp. 280-299.

Wagner, S.M., \& Bode, C. (2008). An Empirical Examination of Supply Chain Performance along Several Dimensions of Risk. Journal of Business Logistics, 29(1), pp. 307-325.

Wang, M., Jie, F. \& Abareshi, A. (2014). The measurement model of supply chain uncertainty and risk in the Australian courier industry. Operations and Supply Chain Management: An International Journal, 7(3), pp. 89-96.

Zsidisin, G.A. (2003a). A grounded definition of supply risk. Journal of Purchasing and Supply Management, 9(5), pp. 217-224.

Zsidisin, G.A. (2003b). Managerial Perceptions of Supply Risk. Journal of Supply Chain Management, Winter, pp. 14-25.

Zsidisin, G.A., \& Ellram, L.M. (2003). An Agency Theory Investigation of Supply Risk Management. Journal of Supply Chain Management, Summer, pp. 15-27.

Zsidisin, G.A., Melnyk, S.A., \& Ragatz, G.L. (2005). An institutional theory perspective of business continuity planning for purchasing and supply management. International Journal of Production Research, 43(16), pp. 3401-3420.

Zsidisin, G.A., \& Smith, M.E. (2005). Managing Supply Risk with Early Supplier Involvement: A Case Study and Research Propositions. Journal of Supply Chain Management, Fall, pp. 44-57.

Samuel K. Formby is the Associate Dean of Undergraduate Programs and an Assistant Professor in the Walker College of Business, Computer Information Systems and Supply Chain Management Department. He spent nearly 30 years in operation management in industry prior to earning his Ph.D. from the Moore School of Business at the University of South Carolina. 
Manoj K. Malhotra is the Jeff B. Bates Professor in the Darla Moore School of Business, and has served as the Chairman of the Management Science Department at the University of South Carolina, since 2000. He is also the founding Director of the Center for Global Supply Chain and Process Management (GSCPM), which was established at the Moore School in 2005. engineering undergraduate degree from The Indian Institute of Technology (IIT) Kanpur, India in 1983, and a Ph.D. in operations management from The Ohio State University in 1990. He is a Fellow of the American Production and Inventory Management Society (CFPIM), and a Fellow of the Decision Sciences Institute (DSI). 